\title{
Improving accuracy of LiDAR-derived digital terrain models for saltmarsh management
}

\author{
M. Fernandez-Nunez ${ }^{1,2} \cdot$ H. Burningham ${ }^{1}$ - J. Ojeda Zujar $^{2}$
}

Received: 3 November 2016/Revised: 27 December 2016 / Accepted: 29 December 2016 / Published online: 8 February 2017

(C) The Author(s) 2017. This article is published with open access at Springerlink.com

\begin{abstract}
Accurate digital elevation models of saltmarshes are crucial for both conservation and management goals. Light detection and ranging (LiDAR) is increasingly used for topographic surveys due to the ability to acquire high resolution data over spatially-extensive areas. This capability is ideally suited to saltmarsh environments, which are often vast, inaccessible systems where topographic variations can be very subtle. Derivation of surface (DSMs) (ground elevation plus vegetation) versus terrain (bare ground elevation) models (DTMs) relies on the ability of the LiDAR sensor to accurately record multiple returns. In saltmarshes however, the dense stands of low $(<1 \mathrm{~m})$ vegetation commonly found precludes the acquisition of more than one return, and the resulting DTM is not different to the DSM. Establishing the offset between ground and vegetation surface in order to correct the LiDAR-derived DTM can be challenging due to the spatial variability in saltmarsh habitats. Here we show the development and application of a habitat-specific correction factor (HSCF) for the Odiel Saltmarshes using a combination of habitat object-based classification (82\% overall accuracy) and ground control surveys that reduces the DTM error to within that associated with the LiDAR sensor (average error $0.1 \mathrm{~m}$ ). We also show that the true accuracy of supplied (unmodified) DTMs can be $>0.5 \mathrm{~m}$ in saltmarshes dominated by dense vegetation such as Spartina densiflora. In particular, global projections of sea-level rise across the next 80 years
\end{abstract}

M. Fernandez-Nunez

miriam.nunez.10@ucl.ac.uk

1 Geography Department, University College London, Pearson Building, Gower Street, London WC1E 6B, UK

2 Departamento de Geografía Física y AGR, Universidad de Sevilla, Calle Maria de Padilla sn, 41004 Sevilla, Spain
$(0.18-0.59 \mathrm{~m})$ significantly overlaps this accuracy margin, implying that assessments and modelling of sea-level impacts in saltmarsh systems will likely be erroneous if based on Lidar-derived DTMs. Erroneous assumptions and conclusions can result if the real accuracy of DTMs (bare ground) on vegetated saltmarshes is not considered, and the consequences of the propagation of this misinformation through to management decisions should not be over-looked.

Keywords DTM · DSM · Vegetation · Saltmarsh mapping · Wetland

\section{Introduction}

LiDAR technology is very useful for the characterisation, quantification and monitoring of coastal environments (Chust et al. 2008; Krolik-root et al. 2015; Mitasova et al. 2010) particularly for saltmarshes, where subtle variations in micro-topography can be crucial for determining spatial patterns in vegetation distribution and edaphic factors (e.g., oxygen and moisture). LiDAR data has been employed in saltmarsh research for purposes such as wetland characterisation (e.g. Morris et al. 2007; Rosso et al. 2006; Millette et al. 2010), vegetation mapping and assessment (e.g. Brown 2004; Rosso et al. 2006; Collin et al. 2010; Yang and Artigas 2010), determination of wetland vegetation height (e.g Genc et al. 2004), evaluation of sea level rise (SLR) impacts (e.g. Webster et al. 2006; Feagin et al. 2010), saltmarsh restoration (e.g. Millard et al. 2013; Athearn et al. 2010) and the detection of estuarine and tidal river hydromorphology (e.g. Gilvear et al. 2004). However, in these low-topography environments, despite resolution improvements offered by LiDAR technology in comparison with other techniques (e.g. NASA Shuttle Radar Topography Mission), the uncertainty in derived 
elevation products can vary significantly between surface types, and is particularly problematic in environments comprising dense vegetation (Hladik and Alber 2012; Schmid et al. 2011). This issue is due to limited penetration of the laser beam through the marsh vegetation layer (Schmid et al. 2011). Erroneous assumptions and conclusions can result if this limitation is not considered, and the consequences of the propagation of this misinformation through to management decisions should not be over-looked.

In saltmarshes, LiDAR systems can fail to distinguish centimetre-scale variations between the vegetation canopy (digital surface model - DSM) and bare-ground/bare-earth (digital terrain model - DTM) (Hopkinson et al. 2004; Schmid et al. 2011). Ground filtering is the primary step required for DTM production (Meng et al. 2010), which is particularly challenging in saltmarsh environments due to the physical structure of vegetation. Many halophytes comprise a dense and homogeneous structure. This means the halophytic vegetation often simulates a flat surface consistent with bare-ground elevation and morphology (Brovelli et al. 2004; Göpfert and Heipke 2006). This characteristic complicates the filtering process because is very difficult to discern if the last return is vegetation or bare-ground.

On the basis that there are limitations for the use of LiDAR in saltmarshes, and the need for high accuracy data in research and management applications in these environments, some authors (e.g. Hladik and Alber 2012; Hopkinson et al. 2004; Populus et al. 2001; Schmid et al. 2011; Millard et al. 2013) have investigated the vertical accuracy of the elevation data from LiDAR, and the possibilities of calibration for these environments (Table 1). For example, several studies (Montané and Torres 2006; Rosso et al. 2006; Schmid et al. 2011) that focus on Spartina alterniflora marshes note that elevations within LiDAR-derived DTMs are overestimated with a mean error between 7 and $17 \mathrm{~cm}$ depending on study site, where the error seems to increase with vegetation density and height (Montané and Torres 2006; Morris et al. 2007; Rosso et al. 2006; Schmid et al. 2011).

Under the physical limitations mentioned previously, LiDAR-derived DTMs covering saltmarshes are generally not accurate enough to distinguish topographic structure at the resolution that is used to determine tidal flooding or vegetation patterns (Hladik and Alber 2012; Krolik-root et al. 2015). Thus, a corrected DTM becomes essential for certain applications (e.g. tidal flooding) in saltmarshes characterised by dense evergreen vegetation, such those found in southern Europe. Previous works in saltmarshes have investigated and applied the minimum bin gridding method (e.g. Ewald 2013; NOAA 2010; Schmid et al. 2011), analysis of airborne infrared photography taken during a rising tide (Andrade et al. 2014) and species-specific correction factors (e.g. Hladik and Alber 2012; McClure et al. 2015) for 'user-modified' DTM creation. In the case of using specific correction factors for correcting LiDAR-derived DTM, the work carried out by Hladik and Alber (2012) and Hladik et al. (2013) in a saltmarsh in Georgia (Atlantic coast, USA), and by McClure et al. (2015) in a saltmarsh in San Francisco bay (Pacific coast) showed that the DTM mean errors can be significantly reduced using this method. However, accurate vegetation maps are required for its appliance over large areas.

In saltmarshes, accurately mapping detailed features from optical remotely sensed data is a challenge due to the low spectral contrast between plant species, and the small scale of vegetation patterns. These particular features have been identified as the main limitations in saltmarsh mapping by different authors in the literature (e.g. Silva et al. 2008; Adam et al. 2009; Kelly et al. 2011; Millard et al. 2013) complicating the classification process more than in other coastal environments. Due to the difficulties in separating saltmarsh plant species or communities, some authors have included elevation data in the classification process to distinguish species of low spectral contrast located at different elevations within the marsh (Chust et al. 2008; Gilmore et al. 2008; Arroyo et al. 2010). This is possible because there is a strong relationship between species and elevation (Silvestri et al. 2005).

The aim of this paper is to investigate the effectiveness of using elevation ground control points (differential GPS) and vegetation surveys to improve vertical accuracy in a LiDARderived DTM for an Atlantic-Mediterranean saltmarsh, through the application of habitat-specific correction factors in the Odiel saltmarshes (Spain, Gulf of Cadiz). Essential to this process is the availability of a high-resolution habitat map, and here we undertake an object-based image classification including high spatial resolution aerial photography and elevation data (DSM) for this purpose.

Although similar approaches have previously been applied (e.g. Hladik and Alber 2012; Hladik et al. 2013; McClure et al. 2015) to reduce mean vertical error in LiDAR-derived DTMs, all previous studies were conducted in the USA. Saltmarsh habitats in the US, especially those found in the Atlantic coast present dissimilarities to those located in Europe due to a range of differences in, for example, extent, vegetation type and structure. For example, saltmarshes in the Gulf of Cadiz comprise complex creek networks compared with the broad coastal tidal plains of the Atlantic US coast (Phinn et al. 1996). Saltmarshes found on the Pacific US coast, particularly in California, present more similarities to Atlantic-Mediterranean saltmarshes in the Gulf of Cadiz (Peinado et al. 1995) than those found in the Atlantic US coast, although species composition is distinctly different (e.g. S. pacifica vs S. perennis; Sp. foliosa vs $S p$. densiflora and $S$. emerisi vs $S$. ramosissima are respectively associated with Pacific US and Gulf of Cadiz coasts). Thus, the success of this method applied to those saltmarshes found in the Gulf of Cadiz could vary based on these dissimilarities due to the difficulties related to saltmarsh species and habitat mapping. Thus, it is still unknown whether the use of habitat- 
Table 1 Studies focused on calculating LiDAR vertical accuracy in saltmarshes

\begin{tabular}{llll}
\hline Purpose & Marsh type & Error (cm) & References \\
\hline Accuracy assessment & Tidal flats/marsh & $10 / 20$ & $\begin{array}{l}\text { Populus et al. (2001) } \\
\text { Morris et al. (2005) }\end{array}$ \\
& Spartina alterniflora & $7-17$ & $\begin{array}{l}\text { Montané and Torres (2006) } \\
\text { Rosso et al. (2006) } \\
\text { Schmid et al. (2011) }\end{array}$ \\
& Upland/Marsh & $18.2 / 45.7$ & $\begin{array}{l}\text { Hladik and Alber (2012) } \\
\text { Millard et al. (2013) }\end{array}$ \\
$\begin{array}{l}\text { Separation of ground } \\
\text { and low vegetation signature }\end{array}$ & Tidal marsh & $2 / 32$ & Wang et al. (2009) \\
\hline
\end{tabular}

specific correction factors can effectively reduce DTM vertical errors in all saltmarsh environments.

\section{Material and methods}

The approach undertaken here (Fig. 1) uses remotely sensed data acquired in a combined photogrammetric and LiDAR flight, that in combination with vegetation surveys and object-based image analysis (OBIA) enables its application over large saltmarsh extensions. The production of a highresolution habitat map is central to this approach in terms of facilitating the spatially-variable application of the habitatspecific correction factor (HSCF) to the input (unmodified) LiDAR-derived DTM. The habitat map is derived from high resolution multispectral aerial photography (using RGB and NIR bands) and unmodified LiDAR data (DSM and Slope). The acquisition of field data, comprising measurements of precise elevation, vegetation structure and plant species assemblages, provided the information need for cover class definition as well as the means to calibrate and validate the correction factor and the classification results.

\section{Study area}

The study area is located within the Odiel saltmarshes of the Odiel-Tinto estuary (Fig. 2) (Gulf of Cadiz, SW Spain), comprising roughly 3000 ha of saltmarsh land. The Tinto-Odiel estuary (the estuarine confluence of the Odiel and Tinto rivers) is situated in the central part of the Huelva coast on the southwest Atlantic coastline of the Iberian Peninsula. This estuary comprises extensive saltmarsh land, vegetated sand spits, coastal sand dunes, beaches and saline lagoons. Two study sites have been selected to test the method. The first site (Site 1) is approximately 10 ha and located in Saltes Island (Fig. 2). Habitats here are typical of those found throughout the mid-high and lower Odiel estuary saltmarshes with a dominance of Salicornia species: high marsh (S. machrotaschyum, and $S$. fruticosa), mid marsh (S. perennis subsp. alpini and Atriplex portulacoide), low marsh (mixture of $S$. perennis subsp. perennis, Atriplex portulacoide and Limonium sp.), creeks and intertidal flats. The second site (Site 2) covers nearly 4 ha and is located in the upper estuary, near the town of Corrales (Fig. 2). This site provides good examples of salt pans and mid- and high marsh habitats dominated by Spartina densiflora, which it poorly represented in Site 1.

\section{Field data}

In order to investigate habitat distribution and composition, a broad vegetation survey was undertaken in September 2012 for the whole study area, where vegetation was surveyed using a $1 \times 1 \mathrm{~m}$ quadrat during low tide. In total, 156 sites were sampled across the Odiel saltmarshes (Fig. 2). Quadrats were located using a semi-random number based positioning process. In each quadrat, plant species cover, bare ground cover and vegetation height per species were measured using visual percentage cover estimations and sward height (Van der Graaf et al. 2002) respectively. These data were analysed using TWINSPAN (version 2.3), which allows clustering of species into indicator-species defined communities (Hill and Šmilauer

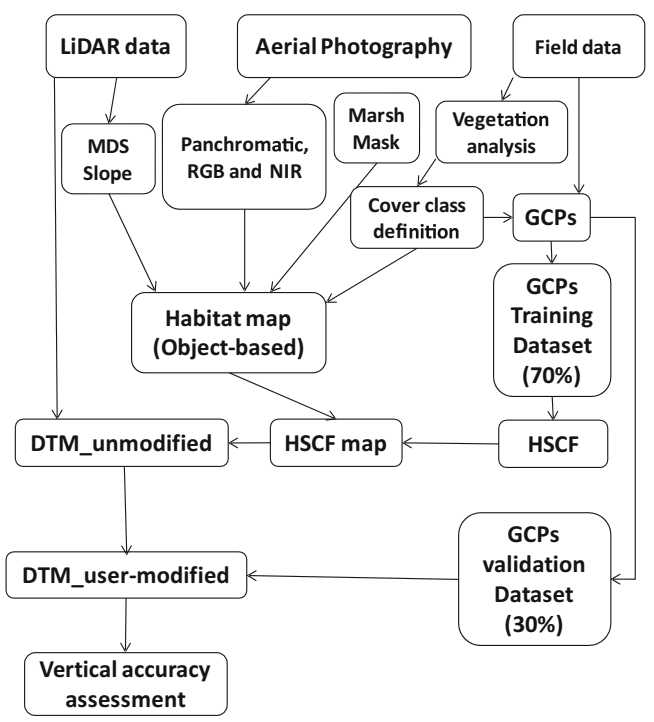

Fig. 1 Workflow of the analytical approach used here 
Fig. 2 Study area and site locations at the Tinto-Odiel estuary (Huelva, Southwest Spain). The GCPs collected for both sites are represented by black dots and the vegetation survey (quadrats) location by white dots

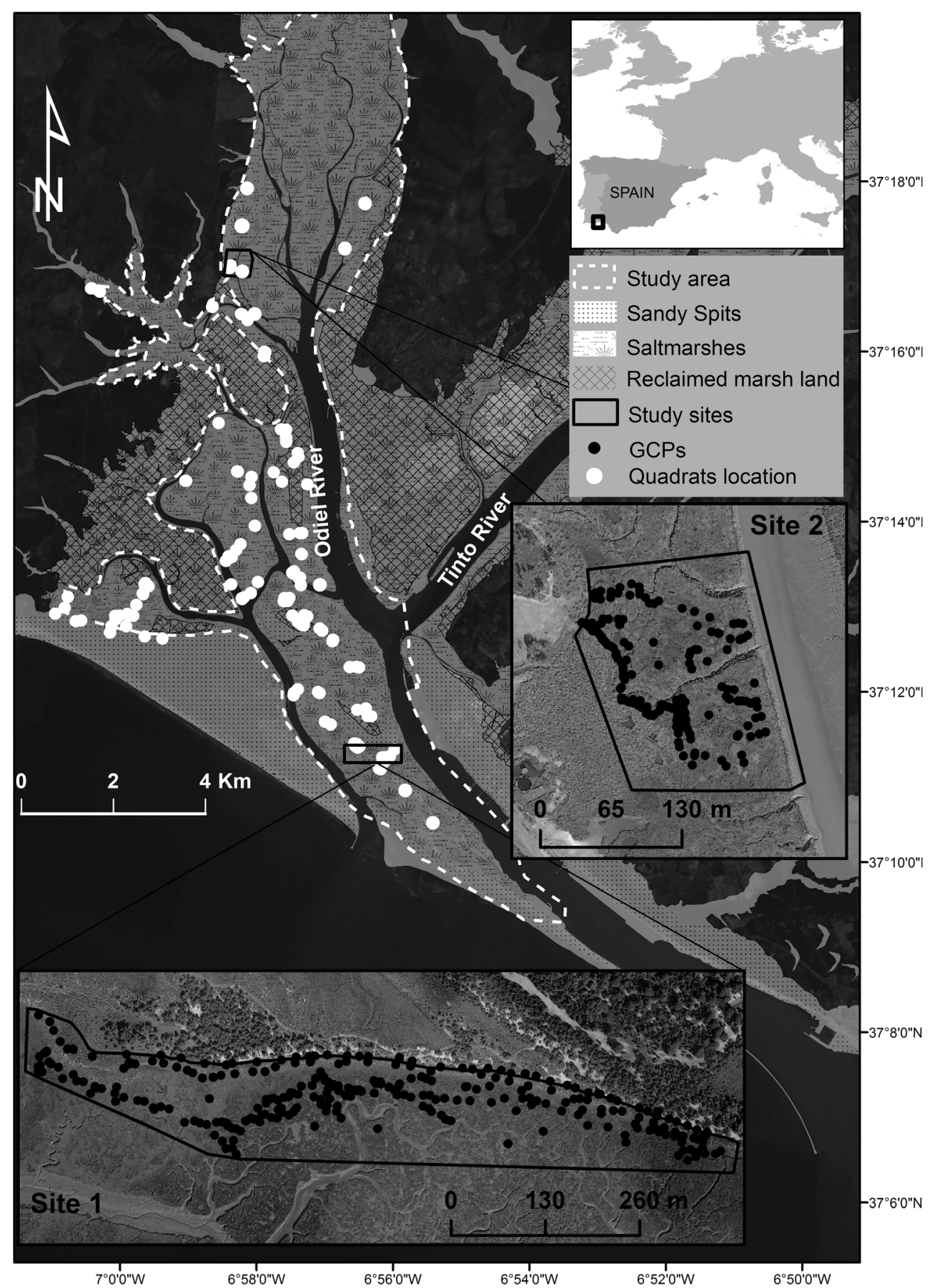

2005). Species vegetation height was then assessed in each of these communities to inform the definition of habitat classes that expressed both plant communities and vegetation structure. Some species, such as $S$. fruticosa and S. densiflora have significantly different growth forms in different areas of the saltmarsh, which is in part related to the local plant community, but also reflects variations in location. The TWINSPAN analysis provided an effective delineation of community, but examination of growth structures enabled a more accurate determination of habitat.
Once the habitat types were defined, a second vegetation height survey was undertaken in November 2012 to support the ascertain that each habitat type displays consistency in canopy height across the whole study area. Here, 12 representative sites covering different habitat types were sampled, where vegetation canopy height was surveyed at 100 randomly located points within a $10 \times 10 \mathrm{~m}$ quadrat. Canopy heights measured in each habitat type from different sites were compared using one-way analysis of variance (ANOVA). Additionally, a Tukey's Honest Significant Difference (HSD) 
test (confidence level $=0.95$ ) was also used. Statistical analyses were performed using the software ' $R$ ' version 2.15.1.

A topographic survey of the saltmarsh was also undertaken in November 2012 at the testing sites. For this, ground control points (GCPs) - 260 within Site 1 and 132 within Site 2 - were established, at which ground elevation, canopy height and plant species presence at were recorded (Fig. 2). Ground elevation at the GCPs was surveyed using a Real-Time Kinematic (RTK) Leica-1200 (base station) GPS and two rovers with $0.02 \mathrm{~m}$ vertical and $0.01 \mathrm{~m}$ spatial accuracy. The RTK Rover foot was placed flush with the marsh surface for ground elevation points. Orthometric heights (in metres above Zero in Alicante) were calculated from RTK elevations using the Spanish Geodetic Survey GEOID (as used for LiDAR elevations) EGM08-REDNAP ("Red Espanola De Nivelacion de Alta Precision", Spanish High Precision Positioning Network). The 392 GCPs collected within the study sites were divided into training (70\% of the GCPs; $N=282)$ and validation data sets (30\% of the GCPs; $N=121$ ). In addition, 20 GCPs were also collected over bare areas (bare ground and roads) for assessing the accuracy of the LiDAR data.

\section{Remote sensing data}

A LiDAR dataset was acquired in a combined LiDAR sensor (Table 2) and photogrammetric camera carried out in January 2013 for a broader research project (Ojeda et al. 2014). Data were collected for the whole Odiel estuary during low tide (tide level $=-1.1 \mathrm{~m}$ above MSL; tidal coefficient $=89$ ) to minimize the amount of water on the marsh surface. The sensor collected up to 4 returns on upland areas (mean point density $=2$ points per square metre), but for the majority of the estuarine environment, only one return was collected. Reported vertical and horizontal accuracies for the LiDAR sensor are $0.07-0.10 \mathrm{~m}$ and $0.15-0.17 \mathrm{~m}$ respectively (Ojeda et al. 2014). Simultaneously, high resolution aerial photography (red, green, blue, NIR, and panchromatic bands) was also obtained with $0.15 \mathrm{~m}$ spatial resolution.

The final products of this flight were: raw LiDAR data ('LAS' files), multispectral aerial photographs (102 photograms), DSM and DTM. Across the saltmarsh and intertidal environment however, only one return was recorded, meaning the 'LAS' files provide little further information for modelling the ground surface in this system. Thus, the DSM and the DTM are identical across the saltmarsh: this unmodified elevation dataset is referred to here as the LiDAR-derived DTM, and was resampled to $1 \mathrm{~m}$ resolution. Elevations were positioned in the Spanish vertical reference frame (Cero in Alicante - the equivalent of mean sea level) and projected onto the UTM (WGS-1984) coordinates (zone 29 N) system.

The discordance between ground elevation and LiDAR survey dates arose due to weather conditions: the LiDAR
Table 2 Details of the LiDAR flight undertaken in January 2013

LiDAR Flight

\begin{tabular}{ll} 
Sensor name & ALS50 II (Leica) \\
Flight height & $1450 \mathrm{~m}$ \\
Pulse frequency & $145.3 \mathrm{kHz}(145,300$ pulses/s) \\
Altimetry precision expected & $0.1 \mathrm{~m}$ \\
Number of Collected returns & 4 \\
Recorded intensity & Once per pulse \\
Multiples Pulses in Air & Yes \\
Points density & 2 points per $\mathrm{m}^{2}$ \\
\hline
\end{tabular}

flight had been planned to coincide with the field survey, but was delayed to January (when weather and low tide conditions were optimum). The tide coefficient was similar to that of the ground survey. Although not ideal, both surveys were still undertaken within the same winter period, thereby reducing the potential for significant change between surveys. Furthermore, except $S$. ramosissima most of the saltmarsh plant species found in Odiel saltmarshes such as S. fruticosa, S. perennis, A. macrostashyum and $S$. densiflora are perennial (Figueroa et al. 1987), which enables a stable evergreen vegetation canopy over the saltmarsh through the whole year. This has been checked and confirmed during numerous field campaigns (associated with another project) undertaken throughout the year.

\section{Habitat mapping}

A high resolution habitat map was produced through the application of object based image analysis (OBIA) on a combined data product covering the specific region of interest covering just the saltmarsh region (Fig. 2). Water and nonmarsh habitats (supratidal spits, reclamations) were masked. The source layers were multispectral photography (January 2013) comprising panchromatic, near-infrared, red, green and blue bands, the LiDAR-derived DSM and the associated slope raster (all in tiff format). Layers were resampled to $1 \mathrm{~m}$ for spatial consistency. The classes used for the classification as well as for training and validation samples were the habitat classes defined using TWINSPAN classification and vegetation height (classes are listed in the results).

The vegetation data collected at each quadrat during the field surveys were used as ground-truth data for image classification validation purpose. Quadrat locations were added as a point layer into ArcGIS 10.2 overlapping the 2013 multispectral photography and validation polygons were digitised around each point following homogeneous vegetation that represented the contiguous habitat patch associated with each quadrat location. Digitisation of the training areas on the other hand were based on extensive image photointerpretation 
experience and knowledge of the study site (supported by 1000 geo-located ground photographs) and an earlier vegetation map (2003) published by the Andalusian Environmental Agency - Consejeria de Medio Ambiente. In total, 316,012 pixels were used for supervised classifier training and 66,480 for validation of the image classification results.

The OBIA approach was performed in two steps using eCognition Developer software (v. 8.7). The first step was to apply the Multi-Resolution Segmentation (MRS) algorithm integrated in eCognition (Benz et al. 2004; Moffett and Gorelick 2013) to the source layers. As described in Benz et al. (2004), MRS is a region growing method that groups randomly selected pixels in a scene into objects using automated merger decisions based on a homogeneity criterion and scale parameter. The optimal scale parameter for this analysis was 10 to enable identification of small creeks and ponds, which are the smallest features of interest here. Inclusion of the LiDAR-derived DSM layer in the segmentation process led to the generation of objects with similar canopy heights (laser penetration is very low in vegetated areas due to the high vegetation density). The second step was to apply the image classification to the objects previously created. The K-nearest neighbour (KNN) classifier (Kim et al. 2011) algorithm was used to perform the classification (five neighbours were used here). The classifier was trained using the training areas (digitised polygons previously created) and included spectral and spatial variables.

\section{DTM correction based on HSCF and habitat map}

The habitat-specific correction factor (HSCF) was based on the vertical bias, or mean error, of the LiDAR-derived DTM with respect to the ground-truth data (the training GCPs). Ground elevations surveyed at $70 \%$ of the GCPs were compared to the DTM elevation values for the same locations. The difference between these two values at each GCP was used to first compute the vertical bias, and second, summarised as a mean correction factor for each habitat type. The vertical bias $\left(\mathrm{CF}_{\mathrm{i}}\right)$ has been previously used to compute correction factors for saltmarshes in Hladik and Alber (2012) and it is calculated as stated in eq. (1):

$C F_{i}=Z_{D T M i}-Z_{G C P i}$

where $Z_{D T M i}$ is the elevation derived from the LiDARderived DTM, and $Z_{\mathrm{GCPi}}$ is the elevation measured by RTK-dGPS, at each GCPi. For each habitat type $\mathrm{j}$, a habitat-specific correction factor $\left(\mathrm{HSCF}_{\mathrm{j}}\right)$ is then computed from the arithmetic mean of all $\mathrm{CF}_{\mathrm{i}}$ that relate to each habitat type.

Application of these habitat-specific correction factors to the Odiel study sites is undertaken using the high resolution saltmarsh habitat cover map (derived from the supervised classification result) which enables the spatialisation of HSCF ( $\mathrm{HSCF}_{\text {map }}$ ), and the correction of the DTM to a usermodified DTM (mDTM) using eq. (2):

$Z_{m D T M}=Z_{D T M}-\mathrm{HSCF}_{\text {map }}$

The GCPs validation dataset (30\% of the collected GCPs) was use to validate $\mathrm{mDTM}$ and assess the difference between the LiDAR-derived DTM over vegetated environments (the true accuracy of the original LiDAR product). In order to assist the accuracy assessment, GCPs were also obtained in other non-vegetated areas such as bare mud and roads. The vertical accuracy assessment of both elevation models was carried out using two error metrics: mean error and Root Mean Square Error (RMSE).

\section{Results}

\section{Field surveys}

The vegetation survey showed that vegetation of the Odiel saltmarshes is mainly represented by 8 halophytic genera: Atriplex, Inula, Salicornia, Puccinellia, Limoniastrum, Limonium, Spartina and Suaeda. The TWINSPAN results (Fig. 3) highlighted the most common plant species associations that also reflected specific habitats across the saltmarsh system. The first division in the TWINSPAN results splits the data into two groups; S. perennis subsp. perennis, $S$. ramosissima and bare soil were the indicators of one group, associated with the low marsh, whereas S. fruticosa, A. portulacoides, S. densiflora and S. perennis subsp. alpini, which are associated with the mid- and high marsh, were indicators for the second group. Further divisions split these groups into more specific communities: low marsh I, low marsh II, mid marsh and high marsh.

Within the high marsh community further divisions in TWINSPAN results (4th division; 23 quadrats) showed $S p$. densiflora as a separate community. This specific community was observed in the field forming large homogeneous patches of Sp. densiflora along the upper-mid estuary, and it was quite different to others high marsh communities at the mid- and low estuary. The field evidences supported by the TWINSPAN results led to consider this community as a different habitat type referred to as Spartina marsh. Furthermore, the canopy height of this community was also quite distinct to the other communities. Based on species height data and plant distribution, the low marsh I and II groups were merged into one habitat type (low marsh), and the high marsh group divided into two habitat types (high marsh and Spartina marsh). Thus, the Odiel saltmarshes habitats can be best described as comprising low marsh (S. perennis subsp. perennis, $S$. 


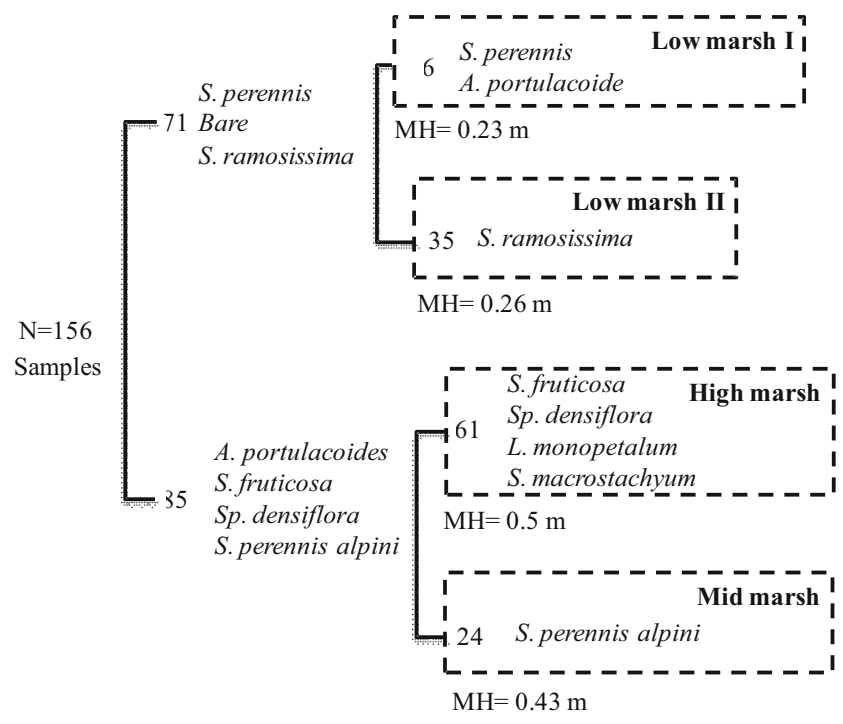

Fig. 3 Dendrogram of Odiel saltmarsh vegetation communities based on TWINSPAN classification. N means the number of quadrats included in each group, and 'MH' the vegetation mean height per group based on species height

ramosissima and bare soil), mid marsh (S. perennis subsp. alpine), high marsh (S. fruticosa, S. macrostachyum, $L$. monopetalum) and Spartina marsh (Sp. densiflora).

The saltmarsh habitats were examined spatially in the context of aerial photography-interpretation leading to the definition of the following saltmarsh cover classes for the habitat classification analysis: low marsh (dominated by short Salicornia spp.), mid marsh (dominated by medium Salicornia spp.), high marsh (dominated by tall Salicornia spp.), Spartina marsh, mud (salt pans and intertidal flats) and water (ponds). The results derived from the field survey justify the use of only 6 classes for a large expanse such as the Odiel saltmarshes. Thus, these cover classes were confidently used for application of correction factors.
Results from the vegetation height surveyed per habitat type are shown in Fig. 4 and show that vegetation height ranged between 0.09 to $1.05 \mathrm{~m}$. Fig. 4 highlights the similarities in canopy height within the habitat types defined here. However, the bottom values of the Spartina marsh height intervals overlap with the top interval values of the high marsh. Canopy heights measured in the different habitats ( 2 sites in low marsh, 3 in mid marsh, 3 in high marsh and 3 in Spartina marsh) were compared using one-way analysis of variance (ANOVA), which proved that there were significant differences in height means between habitats $(p<0.001)$. Additionally, the Tukey's HSD (confidence level $=0.95$ ) clarified that the height means were significantly different between different habitats (results were considered significant when $p<0.05$ ) but were similar among the same habitat type as shown in Fig. 4.

Finally, results from the RTK survey at Site 1 and Site 2 showed that ground elevation ranged from 0.03 to $3 \mathrm{~m}$ in Site 1 and from 1.2 to $2.4 \mathrm{~m}$ in Site 2, and vegetation height from 0.03 to 0.61 and 0.05 and $1.07 \mathrm{~m}$ respectively. These differences are due to the different complexes of habitat present at the different sites; Site 1 represents high marsh (S. machrotaschyum, and $S$. fruticosa), mid marsh (S. perennis subsp. alpini and Atriplex portulacoide) and low marsh (mixture of $S$. perennis subsp. perennis, Atriplex portulacoide and Limonium sp.) dominated by Salicornia species, and Site 2 represents mid- and high marsh habitats dominated by Spartina densiflora. The GCPs were classified by habitat type, divided as 41 points within low marsh class, 153 in mid marsh, 102 in the Salicornia marsh and 96 in the Spartina marsh. Ground elevation measured at each GCP in these different habitats was also compared using oneway analysis of variance (ANOVA), which proved that there were significant differences in ground elevation means between habitat types $(p<0.001)$. Additionally, the Tukey's HSD clarified that the elevation means were significantly different between all habitat types (comparing all habitat types by pairs).

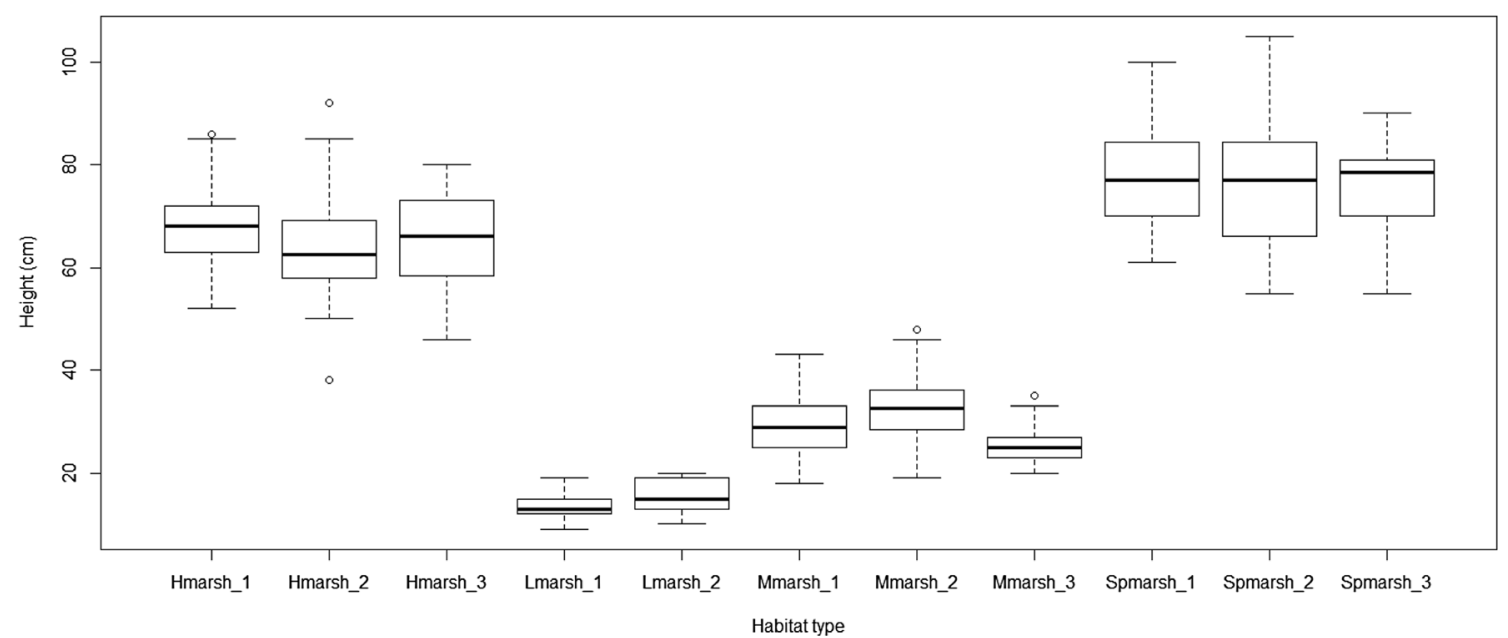

Fig. 4 Vegetation height per habitat type at different sites, where "Lmarsh" means low marsh, "Mmarsh" mid marsh, "Hmarsh" high marsh and "Spmarsh" spartina marsh. The numbers state different sites within the Odiel saltmarshes 
Fig. 5 Marsh habitat map of the Odiel saltmarshes (SW Spain).

The zoom windows represent Site 1 and Site 2

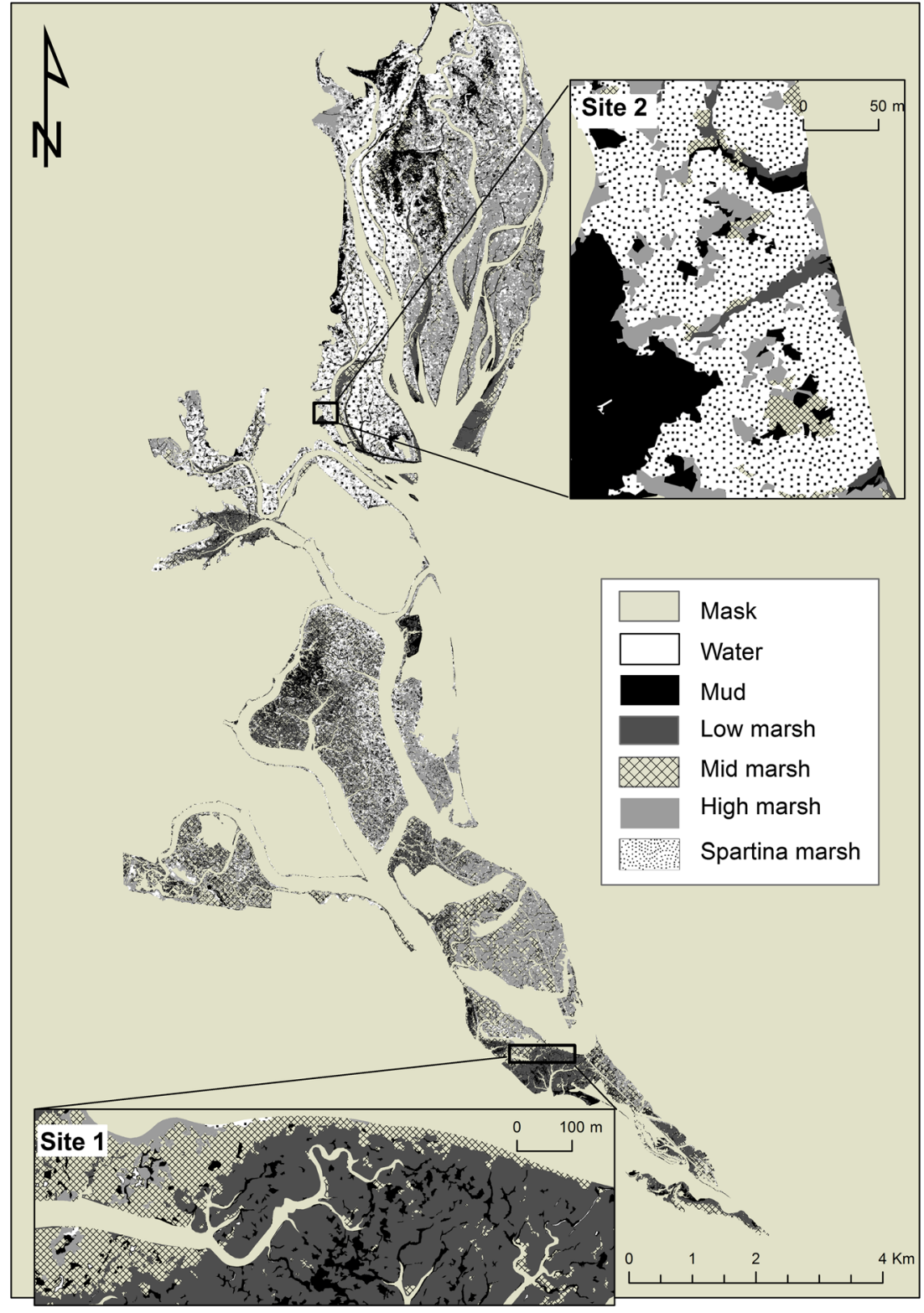

\section{Saltmarsh habitat map}

The classification results are shown in Fig. 5 (including inset maps covering Site 1 and Site 2). The habitat map reveals a complex pattern in the spatial distribution of these habitats. The Spartina marsh, which is characterised by dense and dominant coverage of $S p$. densiflora, and high marsh, characterised by $S$. fruticosa and S. macrostachyum, are most abundant. The Spartina marsh is mainly distributed in the upper estuary, and the high marsh in the mid-estuary. The low and mid-marsh habitats are closely associated in terms of their plant species communities, characterised in the main by $S$. perennis and A. portulacoides, but distinguished by growth structure where plants are notably shorter in the low marsh (S. perennis subsp. perennis, S. ramosissima) areas than in the mid-marsh areas (S. perennis subsp. alpini). Very low density vegetation, bare mud (intertidal flats and salt pans) and water (small creeks and ponds), are found throughout the estuary, but the salt pans are a more prominent feature of the upper estuary. Vegetation is clearly influenced by both elevation and creeks, and patterns of habitat distribution closely follow the creek network (Fig. 5). This is more evident in mature saltmarshes at the mid- and upper estuary where the saltmarsh platform is much higher (up to $1 \mathrm{~m}$ cliff in some parts) than creeks. Low marsh habitats are found following the creek network. For example, Site 1 and Site 2 (Fig. 5) show that broad zonation is determined by the elevation gradient (Fig. 6), but local detail is determined by the presence of creeks.

The overall accuracy of the classification was $82 \%$ and the Kappa coefficient 0.77 as it is shown in the confusion matrix (Table 3). Additionally, we also estimated the user and 
producer accuracy. Focusing on the producer accuracy, which highlights how well the map objects have been classified, we can observe that all the cover classes have been reached values over 70\%. Water, bare mud, low marsh and Spartina marsh were classified with producer accuracy greater than $80 \%(84$, 95, 93 and $82 \%$ respectively), while mid marsh and high marsh under this value (70 and $76 \%$ respectively). Mid marsh and high marsh can be confused by the classifier in those vegetation patches comprising a more complex mix of high and mid marsh vegetation, resulting in slightly lower accuracy values. In the case of the low marsh, the vegetation is usually covered by a mud layer and it can be separated easily from mid and high marsh. Furthermore the average height canopy between low marsh and the rest of classes also play an important role in the classification results, enabling high accuracy values for this class.

\section{DTM production and accuracy assessment}

The HSCFs were only computed for vegetated saltmarsh habitat classes (Table 4) and the un-vegetated classes (mud and water) were added to the mask layer (with a HSCF value of zero) to avoid negative bias. The results highlight that the
Spartina marsh has the highest canopy and the largest standard deviation compared with the other classes. The variability in canopy height (reflected in the standard deviation) is explained by the structure of this plant, which grows in erect clumps of slender stems with long and narrow leaves. Other saltmarsh vegetation is distinctly shorter and less variable.

The HSCF for each habitat class were converted to a spatially-distributed HSCF map using the habitat classification. This was applied as a spatially-distributed correction layer to the unmodified DTM across the whole study area. Comparison of unmodified and corrected DTMs are provided in Fig. 6, for the area covered by Site 1 and Site 2, which highlights the changes in ground elevation as a result of the correction. As it was expected the changes are more pronounced in those areas where the vegetation canopy was higher (i.e. the Spartina marsh). The supratidal zone, channels and bare mud remain the same as these were masked from the analysis. The two profiles (Transect 1 and 2) shown in Fig. 6 illustrate clearly the spatially-varying elevation differences between the LiDAR-derived DTM and the corrected mDTM.

Accuracy was assessed in both the original DEM and corrected mDEM using a selection of ground control points (distinct from those used in the derivation of the correction
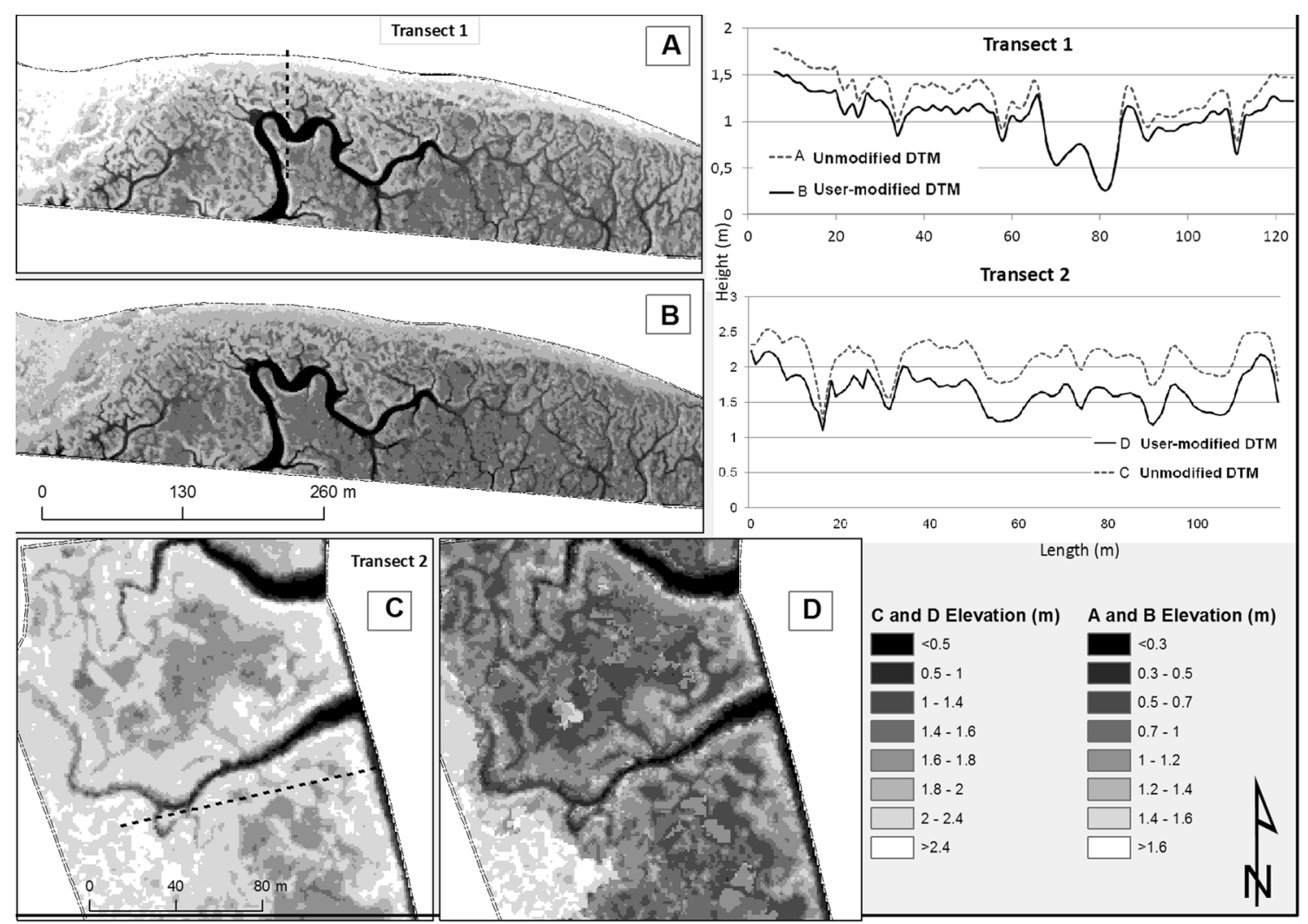

Fig. 6 Map of the two areas used as test sites for unmodified DTM corrections showing the unmodified and user-modifier DTM for Site 1 and Site 2, where: $\mathbf{a}$ and $\mathbf{b}$ are the unmodified and the user-modified DTM respectively in Site 1; and $\mathbf{c}$ and $\mathbf{d}$ are the unmodified and the usermodified DTM respectively in Site 2. Two transects (Transect 1 and
Transect 2) were selected for comparing the height profiles of both DTMs at Site 1 and 2. In the profile graphs, note the differences in canopy heights in the unmodified DTM and the user-modified DTM, and the overlapping at creeks (where a mask was used) 
factors). The results show that the HSCF considerably reduced the overall vertical mean error in both sites (Table 5): from 0.23 to $0.13 \mathrm{~m}$ in Site 1 and from 0.45 to $0.09 \mathrm{~m}$ in Site 2. The unmodified DEM mean vertical error was greater than $0.1 \mathrm{~m}$ (the LiDAR reported mean error) for all habitat classes, except for low marsh. In the case of un-vegetated areas the mean vertical error remained under the reported LiDAR accuracy $(0.1 \mathrm{~m}): 0.09 \mathrm{~m}$ in bare mud areas and 0.04 in roads. In contrast, the mean vertical error in the corrected $\mathrm{mDEM}$ remains well within the reported LiDAR vertical mean error $(0.1 \mathrm{~m})$ for all habitat types except for Spartina marsh (that is slightly higher) as shown in Fig. 7.

The mean vertical biases in the taller and usually denser habitat types (Spartina marsh and High marsh) are significantly decreased from the original DEM to the corrected mDEM: the mean error was reduced from nearly 0.53 to $0.13 \mathrm{~m}$ in Spartina marsh, and from 0.35 to 0.02 in High marsh. The surface level in the rest of habitat classes was all slightly under-predicted in the corrected mDEM due to over estimation of the correction factor: low marsh $(-0.02 \mathrm{~m})$ and mid marsh $(-0.06 \mathrm{~m})$. In order to investigate whether the overestimated correction factor was caused by the averaging technique selected (the mean), the median was also applied. Nevertheless, the results were unchanged when applying a different averaging technique.

\section{Discussion}

LiDAR is one of the sensors that better captures the microscale structural complexity of saltmarsh topography over extensive areas. However, it is extremely important to be aware of the limitations and uncertainty (elevation accuracy) of
DTMs derived from this sensor data for saltmarsh environments, particularly when these data underpin monitoring and management strategies and inform decision-making. Although the LiDAR sensor used for this work collected up to 4 returns, for the majority of the saltmarsh environment only one return was collected as the laser beam was unable to penetrate to the ground. Thus, in the filtering process, it was not possible to discriminate bare ground from saltmarsh vegetation for DTM generation. Based on the analysis undertaken for this work, a LiDAR-derived DTM (without any user modifications) can accurately represent saltmarsh elevations for only non-vegetated (e.g. intertidal flats and salt pans) or low density, short $(<0.2 \mathrm{~m}$ height $)$ plant habitats. The accuracy calculated for these habitats remained below $0.1 \mathrm{~m}$, which is the vertical resolution of the LiDAR data. However, the accuracy of the DTM decreases significantly in habitats characterised by dense, tall vegetation ( $>0.2 \mathrm{~m}$ height). Similar findings have been reported by other authors (Hladik and Alber 2012; Schmid et al. 2011; Wang et al. 2009).

LiDAR-derived DTM accuracy in saltmarsh environments can be improved by user modifications. The development and application of spatially variable correction factors has been shown here to have clear benefits for the mapping of Atlantic-Mediterranean saltmarshes. Application of a correction factor that varies depending on vegetation characteristics reduces vertical errors in vegetated saltmarshes without reducing the spatial resolution. Furthermore, this technique does not compromise the accuracy in open areas such as mud flats if unvegetated areas are masked (where the correction is zero, and therefore no change is made). Masking is often considered an arduous process as it frequently relies on manual digitisation. But habitat classification through an objectbased image analysis approach has the added benefit of
Table 3 K-nearest neighbour confusion matrix for the 6 saltmarsh cover classes. The columns represent the reference data derived from validation areas and the rows the user data derived from the classification results. The producer accuracy shows the accuracy obtained per class (the percentage of pixels that were correctly classified). The cover classes mainly include the following species: high marsh (S. machrotaschyum, and S. fruticosa), mid marsh (S. perennis subsp. alpini and Atriplex portulacoide) and low marsh (mixture of $S$. perennis subsp. perennis, Atriplex portulacoide and Limonium sp.)

\begin{tabular}{|c|c|c|c|c|c|c|c|}
\hline User/Reference class & Water & Mud & Low marsh & Mid marsh & High. marsh & Spar. marsh & Total \\
\hline \multicolumn{8}{|l|}{ Confusion Matrix } \\
\hline Water & 5966 & 0 & 0 & 0 & 0 & 0 & 5966 \\
\hline Mud & 933 & 5273 & 0 & 212 & 0 & 0 & 6418 \\
\hline Low marsh & 121 & 0 & 9389 & 800 & 0 & 640 & 10,950 \\
\hline Mid marsh & 80 & 284 & 613 & 7542 & 376 & 1113 & 10,008 \\
\hline High. marsh & 0 & 0 & 0 & 1805 & 9084 & 2053 & 12,942 \\
\hline Spar. marsh & 0 & 0 & 87 & 450 & 2541 & 17,118 & 20,196 \\
\hline Total & 7100 & 5557 & 10,089 & 10,809 & 12,001 & 20,924 & \\
\hline \multicolumn{8}{|l|}{ Accuracy } \\
\hline Producer $^{\mathrm{a}}(\%)$ & 84 & 95 & 93 & 70 & 76 & 82 & \\
\hline $\operatorname{User}^{\mathrm{b}}(\%)$ & 100 & 82 & 86 & 82 & 70 & 81 & \\
\hline Overall (\%) & 82 & & & & & & \\
\hline Kappa Coefficient & 0.77 & & & & & & \\
\hline
\end{tabular}

${ }^{a}$ refers to the probability of a pixel labeled as a certain class in the map is really this class; and

${ }^{b}$ to the probability of that a certain class on the ground is classified as such 
Table 4 Habitat-specific correction factors (HSCF), the associated standard deviation (SD) and the root mean square error (RMSE)

\begin{tabular}{llll}
\hline Habitat class & HSCF values (m) & SD (m) & RMSE \\
\hline Low marsh & 0.15 & 0.067 & 0.104 \\
Mid marsh & 0.25 & 0.066 & 0.068 \\
High marsh & 0.32 & 0.088 & 0.142 \\
Spartina marsh & 0.55 & 0.16 & 0.292 \\
Mask & 0 & - & - \\
\hline
\end{tabular}

including the identification of small features of unvegetated classes (ponds and salt pans), which can then be assigned to a mask. Thus, negative bias in those areas is avoided.

High resolution habitat classification using object-based image analysis has been used in this work to accurately capture vegetation characteristics on the basis of distinct communities and plant structure. Specific correction factors based on high resolution habitat maps derived from canopy heights and spectral information have the benefits of being applied to broad areas with less effort. However, to map saltmarsh habitats with high accuracy is a challenge due to the low spectral contrast between plant species and the small scale of vegetation patterns (Adam et al. 2009; Kelly et al. 2011; Silva et al. 2008). In this sense, the combination of spectral and elevation information significantly improves saltmarsh mapping (Chust et al. 2008; Gilmore et al. 2008; Yang and Artigas 2010), allowing higher accuracy values. The use of an object-based approach can also improve the classification results in saltmarshes in comparison with pixel-based approaches using high spatial resolution photography (Cao et al. 2007; Ouyang et al. 2011) with poor spectral resolution (four spectral bands).

In the image classification undertaken in this study, we obtained a high overall accuracy (82\%) over a large expanse of saltmarsh. This result is comparable to the values obtained by to Brown (2004) and Belluco et al. (2006) who achived $79 \%$ and $92 \%$ accuracy respectively. However, they applied a pixel-based classification (maximum likelihood classifier) to a smaller saltmarsh area using hyperspectral satellite images

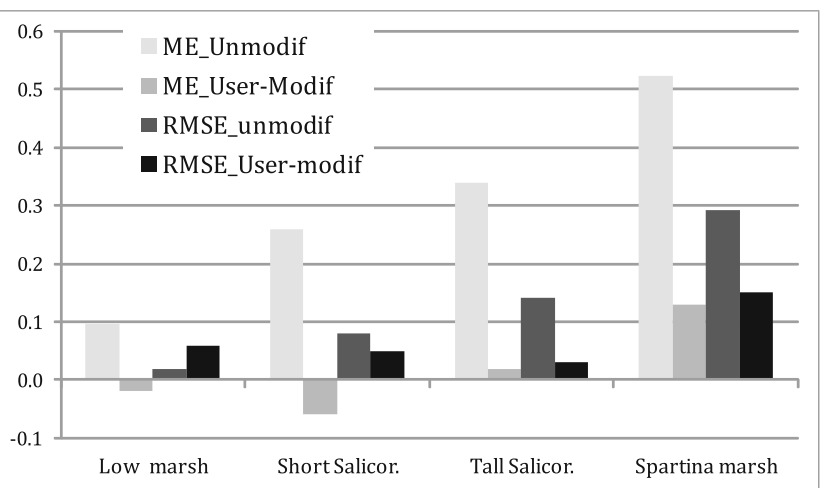

Fig. 7 Mean error (ME) and root mean square error (RMSE) per habitat cover class. The ME and RMSE is compared between the unmodified DTM and the User-modified DTM

(CASI) and elevation data. The high spectral resolution of these images provided more information to discriminate between saltmarsh plants with low spectral contrast. Interestingly, our results showed a higher accuracy for bare mud (96\%) than achieved by Brown (2004) (75\%). The segmentation process previous to the classification has helped in saltmarsh feature recognition in classes such as water and mud, resulting in high individual accuracy values: $84 \%$ water (ponds and small creeks) and 96\% for mud (tidal flats and salt pans). High accuracy in bare mud and low marsh habitat classes are essential to avoid negative bias in these less vegetated habitats. For example, the results showed that low marsh elevation is well modelled by LiDAR-derived DTM and therefore this habitat could be added to the mask layer as well.

Although the correction factors based on habitat maps have greatly improved the LiDAR-derived DTM accuracy, we must be aware of the limitations of this technique when very large surface areas are used. The vegetation height can vary naturally depending on location, and the average technique used to calculate the correction factor values may add negative bias in those places where the vegetation is shorter than the average. This issue could be addressed by classifying each habitat type based on estimated aboveground biomass density as shown in Medeiros et al. (2015). However, for this purpose
Table 5 Error statistic of the unmodified and user-modified DTM for each habitat cover class regard to GCP survey; where 'ME' is the mean error or vertical bias, 'SD' is the standard deviation and 'RMSE' the root mean square error

\begin{tabular}{|c|c|c|c|c|c|c|}
\hline \multirow[t]{2}{*}{ Habitat class } & \multicolumn{3}{|c|}{ Unmodified DTM } & \multicolumn{3}{|c|}{ User-modified DTM } \\
\hline & $\mathrm{ME}(\mathrm{m})$ & $\mathrm{SD}(\mathrm{m})$ & RMSE (m) & $\mathrm{ME}(\mathrm{m})$ & $\mathrm{SD}(\mathrm{m})$ & $\operatorname{RMSE}(\mathrm{m})$ \\
\hline Bare mud & 0.09 & 0.04 & 0.01 & Not used & Not used & Not used \\
\hline Low marsh & 0.09 & 0.09 & 0.02 & -0.02 & 0.08 & 0.06 \\
\hline Mid marsh & 0.26 & 0.11 & 0.08 & -0.06 & 0.13 & 0.05 \\
\hline High marsh & 0.35 & 0.18 & 0.15 & 0.02 & 0.17 & 0.03 \\
\hline Spar. marsh & 0.53 & 0.13 & 0.29 & 0.13 & 0.16 & 0.15 \\
\hline Roads & 0.04 & 0.05 & 0.004 & Not used & Not used & Not used \\
\hline Overall site 1 & 0.23 & 0.13 & 0.07 & 0.13 & 0.14 & 0.06 \\
\hline Overall site 2 & 0.45 & 0.19 & 0.24 & 0.09 & 0.18 & 0.16 \\
\hline
\end{tabular}


aboveground biomass density data collected in the field at the same time period that the aerial photography and DTM is required. The combination of these two techniques (correction factors and aboveground biomass density) would allow a subclassification of each habitat in low and high density for instance (estimating the average height for each sub-class), thereby improving the adjustment of the LiDAR-derived DTM over very large areas. Substantial additional surveying effort is required however to obtain concurrent aboveground biomass density data.

Finally, the corrected DTM obtained after application of the HSCF across the entire Odiel estuary saltmarsh environment has improved the overall accuracy of the ground elevation data, obtaining comparable results to those achieved by Hladik and Alber (2012) and McClure et al. (2015) in northAmerican saltmarshes. The approach outlined here provides a rigorous methodology that can be applied to improve the accuracy of saltmarsh elevation datasets that is thus robust and suitable to support and inform the management of these environments. In particular, elevation accuracy is crucial for modelling the response of saltmarshes to sea-level rise because subtle changes in topography affect other factors that control saltmarsh dynamics (e.g. flooding and soil salinity) (Tabot and Adams 2013). Projections of future global sealevel rise vary from $0.18-0.59 \mathrm{~m}$ (over the period 1980 1999 and 2090-2099) based on physical models (Meehl et al. 2007a, 2007b). This means that the DTM accuracy has to be smaller than sea-level rise projections over these reasonable timescales in order to accurately investigate potential impacts. In the LiDAR dataset presented here, the best accuracy in elevation data that can be obtained is $0.1 \mathrm{~m}$, which is the real accuracy of the elevation raw data collected from LiDAR sensor at up-land known locations. However, it has been shown that the real accuracy of the original DTM in the Odiel saltmarshes is higher than $0.1 \mathrm{~m}$ (up to $0.53 \mathrm{~m}$ in Spartina marsh for instance) due to the high density of the vegetation canopy. Thus, the unmodified DTM in this particular case would not be suitable for modelling sea-level rise effects over the Odiel saltmarsh due to the mean vertical bias in large areas of the saltmarsh is nearly the same that the top range of the future sea-level rise projections $(0.59 \mathrm{~m})$. However, the corrected DTM is suitably accurate to distinguish topographic structure at the resolution that is used to determine future flooding due to sea-level rise.

\section{Conclusions}

The work undertaken here highlights that LiDAR data do not provide accurate DTMs for vegetated saltmarsh environments without the application of additional corrections to the elevations acquired. This is potentially a limitation to the use LiDAR-derived DTMs in applications and investigations that require high accuracy such as tidal flooding, sedimentation and vegetation patterns, and management and conservation activities. The LiDAR elevation error was significantly larger for vegetated saltmarsh areas than the reported LiDAR accuracy $(<0.1 \mathrm{~m})$; un-vegetated areas (e.g., roads and bare mud) were well within this error. Thus, it is highly recommended to check the real accuracy of the LiDAR-derived DTM before starting to work with these data. Errors in the vegetated marsh areas of the unmodified DTM range between 0.1 and $0.53 \mathrm{~m}$, showing a high variability among habitat types. Error magnitude was greatest in Spartina marsh habitats, and generally increased with the vegetation height and density. This study demonstrates that application of habitat-specific correction factor is a suitable approach for improving DTM accuracy in Atlantic-Mediterranean saltmarshes. After applying the correction factors, the error of the corrected DTM was lower than the reported LiDAR accuracy $(0.1 \mathrm{~m})$ for all habitat types, except for the Spartina marsh that was slightly higher $(0.13 \mathrm{~m})$. In addition, high resolution habitat maps based on canopy heights are appropriated tools for applying correction factors to large study areas as it has been shown in this work.

Finally, this research also showed the importance of elevation accuracy in low-lying areas like saltmarshes and highlights the need for DTM corrections when certain applications such sea-level rise projections are used. In this sense, this work offers saltmarsh managers a robust approach that can be followed to modify LiDAR-derived DTMs, providing the accuracy required for evaluating saltmarsh change in a context of sea-level rise.

Acknowledgements The current study has been developed within two research projects: one funded by the Spanish National Research Plan and European Regional Development Fund (ERDF) ("Detail mapping and web dissemination of demographic, tourist and environmental data for vulnerability assessments linked to beach erosion in the Andalusia Coast (sea-level rise associated to climate change)"; CSO2010-15807) and the other one by Andalusia regional government ("Espacialización y Difusión Web de Datos de Urbanización, y Fitodiversidad para el Análisis de Vulnerabilidad ante los Procesos de Inundación Asociados a la Subida del Nivel del Mar en la Costa Andaluz"; RNM-6207).

Open Access This article is distributed under the terms of the Creative Commons Attribution 4.0 International License (http:// creativecommons.org/licenses/by/4.0/), which permits unrestricted use, distribution, and reproduction in any medium, provided you give appropriate credit to the original author(s) and the source, provide a link to the Creative Commons license, and indicate if changes were made.

\section{References}

Adam E, Mutanga O, Rugege D (2009) Multispectral and hyperspectral remote sensing for identification and mapping of wetland vegetation: a review. Wetl Ecol Manag 18:281-296

Andrade F, Blanton J, Ferreira MA, Amft J (2014) Developments in salt marsh topography using airborne infrared photography (chap. 13). In: Finkl CW, Makowsky C (eds) Remote sensing and modelling: 
advances in coastal and marine resources, coastal research library 9. Springer International Publishing, Switzerland, pp 317-331

Arroyo LA, Johansen K, Armston J, Phinn S (2010) Integration of LiDAR and QuickBird imagery for mapping riparian biophysical parameters and land cover types in Australian tropical savannas. For Ecol Manag 259:598-606

Athearn ND, Takekawa JY, Jaffe B, Hattenbach BJ, Foxgrover AC (2010) Mapping elevations of tidal wetland restoration sites in San Francisco Bay: comparing accuracy of aerial Lidar with a Singlebeam Echosounder. J Coast Res 26(2):312-319. doi:10.2112/08-1076.1

Belluco E, Camuffo M, Ferrari S, Modenese L, Silvestri S, Marani A (2006) Mapping salt-marsh vegetation by multispectral and hyperspectral remote sensing. Remote Sens Environ 105(1):54-67

Benz UC, Hofmann P, Willhauck G, Lingenfelder I, Heynen M (2004) Multi-resolution, object oriented fuzzy analysis of remote sensing data for GIS-ready information. J Photogramm Remote Sens 58: 239-258

Brovelli MA, Cannata M, Longoni UM (2004) Research article LIDAR data filtering and DTM interpolation within GRASS. Trans GIS 8: $155-174$

Brown K (2004) Increasing classification accuracy of coastal habitats using integrated airborne remote sensing. EARSeL eProceedings 3(1):34-42

Cao M, Liu G, Zhang X (2007) An object-oriented approach to map wetland vegetation:a case study of yellow river delta. In: IEEE International Geoscience and Remote Sensing Symposium, Barcelona, Spain, pp. 4585-4587

Chust G, Galparsoro I, Borja A, Franco J, Uriarte A (2008) Coastal and estuarine habitat mapping, using LIDAR height and intensity and multi-spectral imagery. Estuar Coast Shelf Sci 78:633-643

Collin A, Long B, Archambault P (2010) Salt-marsh characterization, zonation assessment and mapping through a dual-wavelength LiDAR. Remote Sens Environ 114(3):520-530

Ewald MJ (2013) Where's the Ground Surface? Elevation Bias in LIDAR-derived Digital Elevation Models Due to Dense Vegetation in Oregon Tidal Marshes. Thesis, Oregon State University, USA

Feagin RA, Martinez ML, Mendoza-Gonzalez G, Costanza R (2010) Salt marsh zonal migration and ecosystem service change in response to global sea level rise: a case study from an urban region. Ecol Soc 15(4): 14

Figueroa E, Jimenez-Nieva J, Carranza J, Gonzalez Vilches C (1987) Distribucion y Nutricion Mineral de Salicornia ramosissima J. Woods, Salicornia europaea L. y Salicornia dolichostachya Moss. en el estuario de los rios Odiel y Tinto (Huelva, SO España). Limnetica 3:307-310

Genc L, Dewitt B, Smith S (2004) Determination of wetland vegetation height with LIDAR. Turk J Agric For 28:63-71

Gilmore M, Wilson EH, Barrett N, Civco DL, Prisloe S, Hurd JD, Chadwick C (2008) Integrating multi-temporal spectral and structural information to map wetland vegetation in a lower Connecticut River tidal marsh. Remote Sens Environ 112:4048-4060

Gilvear D, Tyler A, Davids C (2004) Detection of estuarine and tidal river hydromorphology using hyper-spectral and LiDAR data: forth estuary, Scotland. Estuar Coast Shelf Sci 61:379-392

Göpfert J, Heipke C (2006) Assessment of LiDAR DTM accuracy in coastal vegetated areas. Int Arch Photogramm Remote Sens Spat Inf Sci 36:79-85

Hill MO, Šmilauer P (2005) TWINSPAN for windows version 2.3. Centre for Ecology \& Hydrology and University of South Bohemia, Huntingdon

Hladik C, Alber M (2012) Accuracy assessment and correction of a LIDAR-derived salt marsh digital elevation model. Remote Sens Environ 121:224-235

Hladik C, Schalles J, Alber M (2013) Salt marsh elevation and habitat mapping using hyperspectral and LIDAR data. Remote Sens Environ 139:318-330
Hopkinson C, Lim K,Chasmer LE, Treitz P, Creed IF, Gynan C (2004) Wetland grass to plantation forest - estimating vegetation height from the standard deviation of lidar frequency distributions. Int Arch Photogramm Remote Sens Spat Inf Sci 36(8/W2):288-294

Kelly M, Tuxen KA, Stralberg D (2011) Mapping changes to vegetation pattern in a restoring wetland: finding pattern metrics that are consistent across spatial scale and time. Ecol Indic 11:263-273

Kim D, Cairns DM, Bartholdy J (2011) Multi-scale GEOBIA with very high spatial resolution digital aerial imagery: scale, texture and image objects. Int J Remote Sens 31:58-78

Krolik-root C, Stansbury DL, Burnside NG (2015) Effective LiDARbased modelling and visualisation of managed retreat scenarios for coastal planning : an example from the southern UK. Ocean Coast Manag 114:164-174

McClure A, Liu X, Hines H, Ferner MC (2015) Evaluation of Error Reduction Techniques on a LIDAR-Derived Salt Marsh Digital Elevation Model. Just CERFing 6(11):8-17

Medeiros S et al (2015) Adjusting lidar-derived digital terrain models in coastal marshes based on estimated aboveground biomass density. Remote Sens 7(4):3507-3525

Meehl A, Stocker TF, Collins WD, Friedlingstein P, Gaye AT, Gregory JM, Kitoh A, Knutti R, Murphy JM, Noda A, Raper SCB, Watterson IG, Waver AJ, Zhao Z (2007a) Global climate projections. In: Solomon S, Qin D, Manning M, Chen Z, Marquis M, Averyt KB, Tignor M, Miller HL (eds) Contribution of working group I to the fourth assessment report of IPCC on climatic change. Cambridge University Press, Cambridge, pp 749-844

Meehl GA, Covey C, Taylor KE, Delworth T, Stouffer RJ, Latif M, McAvaney B, Mitchell JFB (2007b) The WCRP CMIP3 Multimodel dataset: a new era in climate change research. Bull Am Meteorol Soc 88:1383-1394

Meng X, Currit N, Zhao K (2010) Ground filtering algorithms for airborne LiDAR data: a review of critical issues. Remote Sens 2:833-860

Millard K, Redden AM, Webster T et al (2013) Use of GIS and high resolution LiDAR in salt marsh restoration site suitability assessments in the upper bay of Fundy, Canada. Wetl Ecol Manag 21(4): 243-262. doi:10.1007/s11273-013-9303-9

Millette TL, Argow BA, Marcano E, Hayward C, Hopkinson CS, Valentine V (2010) Salt marsh geomorphological analyses via integration of Multitemporal multispectral remote sensing with LIDAR and GIS. J Coast Res 26(5):809-816. doi:10.2112/JCOASTRES-D09-00101.1

Mitasova H, Hardin E, Overton M, Kurum M (2010) Geospatial analysis of vulnerable beach-foredune systems from decadal time series of lidar data. J Coast Conserv 14(3):161-172

Moffett KB, Gorelick SM (2013) Distinguishing wetland vegetation and channel features with object-based image segmentation. Int $\mathrm{J}$ Remote Sens 34:1332-1354

Montané JM, Torres R (2006) Accuracy assessment of Lidar saltmarsh topographic data using RTK GPS. Photogramm Eng Remote Sens 72:961-967

Morris JT, Porter D, Neet M, Peter A (2005) Integrating LIDAR elevation data, multi spectral imagery and neural network modelling for marsh characterization. International Journal of Remote Sensing, 26 (23): $5221-5234$

Morris JT, Porter D, Neet M, Peter A (2007) International journal of remote integrating LIDAR elevation data, multi - spectral imagery and neural network modelling for marsh characterization. Int J Remote Sens 26:5221-5234

NOAA (2010) LiDAR data collected in marshes: its error and application for sea level rise modeling. NOAA Coastal Services Center, Charleston, $\mathrm{p} 22$

Ojeda J, Diaz P, Prietos A, Alvarez JI, Fernandez-Nunez M et al (2014) Detail mapping and web dissemination of demographic, tourist and environmental data for vulnerability assessments linked to beach 
erosion in the Andalusia coast (sea-level rise associated to climate change). Universidad de Sevilla, Sevilla 58p

Ouyang Z, Zhang M, Xie X, Shen Q, Guo H, Zhao B (2011) A comparison of pixel-based and object-oriented approaches to VHR imagery for mapping saltmarsh plants. Ecol Inf 6:136-146

Peinado M et al (1995) Similarity of zonation within California -Baja California and Mediterranean salt marshes. Southwest Nat 40(4): 388-405

Phinn SR, Stow DA, Zedler JB (1996) Monitoring wetland habitat restoration in Southern California using airborne multispectral video data. Restor Ecol 4:412-422

Populus J, Barreau G, Fazilleau J, Kerdreux M, Yavanc JL (2001) Assessment of the Lidar topographic technique over a coastal area. Proceedings of CoastGIS'01: 4th International Symposium on GIS and Computer Mapping for Coastal Zone Management, Halifax, 11p

Rosso PH, Ustin SL, Hastings A (2006) Use of lidar to study changes associated with spartina invasion in San Francisco Bay marshes. Remote Sens Environ 100:295-306

Schmid KA, Hadley BC, Wijekoon N (2011) Vertical accuracy and use of topographic LIDAR data in coastal marshes. J Coast Res 275:116 132
Silva TSF, Costa MPF, Melack JM, Novo EM (2008) Remote sensing of aquatic vegetation: theory and applications. Environ Monit Assess 140:131-145

Silvestri S, Defina A, Marani M (2005) Tidal regime, salinity and salt marsh plant zonation. Estuar Coast Shelf Sci 62:119-130

Tabot PT, Adams JB (2013) Ocean \& Coastal Management Ecophysiology of salt marsh plants and predicted responses to climate change in South Africa. Ocean Coast Manag 80:89-99

Van der Graaf AJ, Bos D, Loonen MJJE, Engelmoer M, Drent RH (2002) Short-term and long-term facilitation of goose grazing by livestock in the Dutch Wadden Sea area. J Coast Conserv 8:179-188

Wang C, Menenti M, Stoll MP, Feola A, Belluco E, Marani M (2009) Separation of ground and low vegetation signatures in LiDAR measurements of salt-marsh environments. IEEE Trans Geosci Remote Sens 47:2014-2023

Webster TL, Forbes DL, MacKinnon E, Roberts D (2006) Flood-risk mapping for storm-surge events and sea-level rise using lidar for Southeast New Brunswick. Can J Remote Sens 32:194-211

Yang J, Artigas FJ (2010) Mapping saltmarsh vegetation by integrating hyperspectral and LiDAR remote sensing. In: Wang Y (ed) Remote sensing of coastal environments. CRC Press, Florida 